\title{
Teología y política de la libertad religiosa en Norteamérica: cuatro modelos procedentes de la época fundacional
}

\author{
The Theology and Politics of the U.S. Religion Clauses: \\ four Models from the Foundational Era
}

\author{
John WITTE, JR. \\ Emory University School of Law \\ john.witte@emory.edu
}

RECIBIDO: 21/09/2017 / ACEPTADO 20/11/2017

\begin{abstract}
Resumen: En este artículo, el autor analiza los cuatro distintos modelos de libertad religiosa que se pueden distinguir en la época fundacional estadounidense: el modelo puritano, el evangélico, el ilustrado y el cívico-republicano. Los exponentes de estos cuatro modelos a menudo defendieron causas communes y utilizaron un mismo lenguaje, particularmente durante el período de debates de la convención constitucional y ratificación. Sin embargo, cada grupo ofreció su propia doctrina sobre la libertad religiosa y tuvo sus propias preferencias para su implementación en el derecho constitucional. Juntos, se puede decir que estos grupos sostuvieron las cuatro esquinas de un amplio dosel de opinión sobre la libertad religiosa en la América del siglo XVIII.
\end{abstract}

Palabras clave: libertad religiosa; Estados Unidos; siglo XVIII; puritanos; evangélicos; Ilustración; movimiento cívico-republicano.

\begin{abstract}
In this article, the author explores the four distinct models on religious liberty that can be distinguished from the American founding era: Puritan, Evangelical, Enlightenment, and Civic Republican models. Exponents of these four models often found common cause and used common language, particularly during the constitutional convention and ratification debates. Yet each group offered its own distinct teachings on religious liberty and had its own preferences for their implementation in constitutional law. Together, these groups held up the four corners of a wide canopy of opinion about religious liberty in eighteenth-century America.
\end{abstract}

Keywords: freedom of Religion; United States; 18th century; puritans; evangelicals; Enlightenment; Civic Republican Movement.

\section{INTRODUCCIÓN}

E n cierta ocasión, Thomas Jefferson describió las nuevas garantías constitucionales para la libertad religiosa en Norteamérica como un «experimento justo y novedoso» ${ }^{1}$. Dichas garantías, dispuestas por la nueva

* Este trabajo es un extracto adaptado de la obra Religion and the American Constitutional Experiment, $4^{\mathrm{a}}$ ed., Oxford University Press, 2016, cap. 2, de John Witte, Jr. y Joel A. Nichols. Quiero manifestar mi agradecimiento al Prof. Nicolás Zambrana Tévar, por su excelente traducción y al Prof. Rafael Domingo, por su acertado trabajo de edición, así como por su inapreciable ayuda.

1 Padover, S. K. (ed.), The Complete Fefferson, Containing His Major Writings (1943), 538, 673-676, 1147; FoRD, P. L. (ed.), The Works of Thomas Jefferson, 12 vols. (1904-1905), 11:7; BoYD, J. (ed.), The Papers of Thomas Fefferson, 9 vols. (1950), 1:537-539. 
constitución federal, así como por las nuevas constituciones estatales, aprobadas en el período que fue de 1776 hasta 1791, desafiaron la milenaria asunción, heredada de Europa occidental, consistente en lo inevitable de que alguna forma de cristianismo fuera oficialmente establecida ${ }^{2}$ en cada comunidad política y de que el Estado debía protegerla y auspiciarla, frente a cualesquiera otras confesiones. Norteamérica no sufriría más dichas prescripciones y proscripciones en materia religiosa, afirmó Jefferson. Todas las formas de cristianismo tendrían que valerse por sí mismas y en igualdad de condiciones, junto a todas las demás religiones. Su supervivencia y expansión tendrían que estar basadas en la persuasión de su mensaje, no en la coerción de la espada; en la fe de sus miembros, no en la fuerza de la ley.

Ésta era una opinión habitual entre los aproximadamente trescientos padres fundadores principales de la nación norteamericana, que ayudaron a confeccionar las nuevas garantías constitucionales estadounidenses sobre libertad religiosa, así como entre los miles de ciudadanos de la primera hora, que votaron para que se ratificaran tales garantías. Sin embargo, en su desarrollo, los padres fundadores entendieron de diferentes modos dónde habría de ponerse el énfasis y cómo habrían de aplicarse tales garantías. Defendieron sus posturas por medio de todo tipo de géneros literarios: discursos políticos y conferencias propiamente dichas, eruditos tratados y breves panfletos, sermones e invectivas, charlas íntimas y tranquilas conversaciones de sobremesa, así como mediante correspondencia privada y diarios personales, parte de los cuales han llegado hasta nosotros.

Dentro de estas amplias fuentes de la época fundacional se pueden distinguir cuatro modelos o perspectivas diferentes en materia de libertad religiosa, cada una de las cuales tuvo una importancia crucial en la elaboración de la constitución. Las he denominado perspectivas puritana, evangélica, ilustrada y cívico republicana. Los mayores exponentes de estos cuatro modelos y perspectivas hicieron con frecuencia causa común y emplearon un mismo lenguaje, en especial durante los debates de la convención y ratificación constitucionales. Sin embargo, cada grupo ofreció sus propias y distintas enseñan-

2 En castellano es más frecuente utilizar únicamente las expresiones «estado confesional» $\mathrm{o} \ll$ religión oficial», para referirse a la religión que un Estado considera como propia y apoya positivamente, con o sin tolerancia hacia otras religiones. Aquí se ha preferido traducir casi literalmente el verbo «establish», empleado con mucha frecuencia por el autor y por la jurisprudencia norteamericana, al hablar de la acción de «establecer oficialmente» una religión, en el sentido de declarar la estatalidad u oficialidad de una religión determinada ( $n$. del t .). 
zas sobre libertad religiosa, así como cada uno tuvo sus propias preferencias en lo relativo al modo de ponerlas en práctica, mediante el Derecho constitucional. Juntos, estos grupos sostuvieron las cuatro esquinas de un amplio dosel de opiniones en materia de libertad religiosa, en la Norteamérica del siglo XVIII.

La imagen de un «dosel» de opiniones -que oscila y se despliega aunque siga cubriendo el mismo espacio, básicamente- pone de relieve la idea de que las opiniones de los padres fundadores sobre libertad religiosa se resisten a una sencilla descripción y clasificación. Circulaban otras muchas opiniones sobre libertad religiosa, además de las cuatro mencionadas, y para describirlas también pueden emplearse muchas otras etiquetas. Además, los padres fundadores se movían con frecuencia y con facilidad entre dos o más de estas perspectivas, con el tiempo desplazaban sus alianzas y lealtades o modificaban el tono o el ritmo de sus afirmaciones, conforme pasaban del discurso formal al púlpito, al escritorio o a la tribuna política. Estas cuatro perspectivas se presentan aquí como modelos heurísticos: típicos racimos de argumentos y opiniones, percibibles en las discusiones y debates sobre derechos y libertades religiosas, en la Norteamérica del siglo XVIII.

La comprensión original de los padres fundadores, en lo relativo a la libertad religiosa, no puede verse reducida a una sóla de estas perspectivas. Se debe buscar en las tensiones entre ellas y en los principios generales que emergieron de su interacción y este trabajo no puede ofrecer más que unas pocas pinceladas sobre las mismas.

Los padres fundadores de la nación norteamericana sabían que, con la Primera Enmienda de la Constitución, así como con las constituciones de cada estado de la Unión, estaban creando algo nuevo. La novedad residía, especialmente, en sus esfuerzos por suprimir las religiones oficialmente establecidas, a nivel nacional, y por extender la libertad religiosa a todos los creyentes pacíficos. Sin embargo, también entendieron que la tradición occidental proporcionaba numerosos ejemplos en los que apoyarse y que partir de esas fuentes era de vital importancia para lograr algo constitucionalmente convincente y políticamente aceptable para la nueva nación.

En el presente trabajo nos acercamos a los padres fundadores para escuchar de cerca las conversaciones, formales e informales, que mantuvieron entre sí, sobre el origen, naturaleza y finalidad de las nuevas garantías constitucionales para la libertad religiosa. Empleando desde diarios y cartas personales, hasta la propia Constitución y pasando por los debates en los que ésta se discutió y ratificó, a finales del siglo XVIII, dejaremos que sean los propios 
padres fundadores los que nos confíen exactamente lo que trataban de conseguir, con este nuevo experimento.

$\mathrm{Al}$ tiempo que nos embarcamos en este viaje, es importante recordar que el experimento norteamericano de libertad religiosa no puede reducirse a las cláusulas sobre religión incluidas en la Primera Enmienda de la Constitución ${ }^{3}$. El pensamiento de los padres fundadores tampoco puede abarcarse con el mero estudio de los debates que tuvieron lugar durante el primer período de sesiones del Congreso, en 1789. La crónica de estos debates no es sólo muy escasa -tan sólo tres páginas, en una edición moderna- sino que dichas cláusulas religiosas de la Primera Enmienda sólo reflejan, por designio expreso, una pequeña parte del primer experimento constitucional norteamericano, así como de su praxis. Dichas cláusulas constitucionales sólo definen formalmente las fronteras exteriores de una apropiada acción gubernamental ${ }^{4}$ respecto a la religión: «El Congreso no promulgará ninguna ley respecto al establecimiento de una religión, o prohibiendo la libre práctica de la misma ${ }^{5}$. El significado

3 Tanto la jurisprudencia como la doctrina constitucional estadounidense emplean habitualmente la expresión «cláusulas sobre religión» («religion clauses»), para referirse a los artículos, enmiendas o disposiciones constitucionales, en especial de la Primera Enmienda de la Constitución Federal, en las que se recogieron las garantías para la libertad religiosa que posteriormente fueron desarrolladas por el Tribunal Supremo. A pesar de que la expresión inglesa «religion clauses» bien podría traducirse como «disposiciones constitucionales en materia de libertad religiosa», dicha expresión tiene mucha solera en Estados Unidos y también es técnica y lingüísticamente aceptable en castellano, por lo que hemos decidido traducirla literalmente, como hemos hecho con otras expresiones típicas del Derecho constitucional norteamericano $(n$. del $t$.).

4 En Estados Unidos, el término «Government» o «governmental» hace referencia al Estado o a la Administración Pública en general, incluyendo en dicha expresión a los tres poderes estatales clásicos -ejecutivo, legislativo y judicial-y no sólo al poder ejecutivo, como sucede habitualmente en castellano, cuando se hace referencia al «Gobierno» de un país. Sin embargo, el término inglés «Government» es técnicamente correcto para referirse al Estado, en cuanto el Estado es una estructura de poder que «gobierna» una comunidad política. Por otro lado, traducir «Government» por «Administración pública» podría llevar a la errónea conclusión de que las dos expresiones son equivalentes, cuando en realidad el concepto de Administración Pública de origen francés y alemán no es comparable con el de origen anglo-sajón. Más áun, traducir «Government» como «Estado» obligaría a distinguir constantemente entre el «Estado federal» y los «Estados federados», cuando en inglés las referencias a los «states» son habitualmente referencias a los «Estados federados» y las referencias al «Government» son habitual y sencillamente referencias al «Estado federal». No obstante, el término «Government» también se puede encontrar haciendo referencia a los poderes ejecutivo, legislativo y judicial de nivel inferior al federal-nacional: estados federados, condados y municipios. Por último, como sucede con la expresión «religion clauses», se trata un término totalmente aceptado en la doctrina constitucional norteamericana y se ha preferido conservarlo en su integridad ( $n$. del $t$.).

5 Existen diferentes traducciones de la Constitución de los Estados Unidos de América, algunas de las cuales pueden tener incluso algún tipo de valor «oficial», puesto que aparecen en sitios 
preciso de estos términos se dejó abierto al debate y al desarrollo posterior. Más aún, las cláusulas sobre religión solamente vinculaban al Gobierno federal (de ahí la referencia al «Congreso»), convirtiendo las constituciones estatales, así como las opiniones de sus redactores, en fuentes igualmente cruciales para la comprensión del concepto original de libertad religiosa. Finalmente, los redactores de las cláusulas sobre religión urgieron también a los intérpretes a no fijarse únicamente en la intención del redactor sino, en palabras de James Madison, «en el propio texto [y] en el sentido dado al mismo por el pueblo, en sus respectivas convenciones estatales, donde recibió toda la autoridad que posee» ${ }^{6}$. Las convenciones estatales de ratificación interpretaron el texto conforme a sus propios experimentos constitucionales, así como a sus propias experiencias a nivel estatal, parte de las cuales se recogieron en panfletos, sermones, cartas y discursos de la época. Por ello, es necesario consultar una gran cantidad de fuentes textuales y contextuales, del siglo XVIII, si se quiere de veras comprender las ideas que prevalecieron en la joven república norteamericana, en materia de derechos y libertades religiosas ${ }^{7}$.

\section{Perspectivas Puritanas}

Los puritanos ${ }^{8}$ de los estados de Nueva Inglaterra, tales como Massachusetts, Connecticut, New Hampshire, Vermont y Maine, eran los legítimos herederos de la teología sobre libertad religiosa procedente de

de internet del Gobierno de Estados Unidos. Sin embargo, hemos optado por nuestra propia traducción de la Primera Enmienda, por entender que es más cercana tanto al sentido original del texto como al desarrollo jurisprudencial posterior (n. del t.).

6 Madison, J., «Letter from James Madison to Thomas Richie (September 15, 1821)», en Letters and Other Writings of fames Madison, 4 vols. (1884), 3:228. Vid. también la cita de MADISON en The Debates and Proceedings in the Congress of the United States, March 3, 1789; May 27, 1824, 42 vols. (18341856), vol. 5, col. 776: «As the instrument came from [the drafter] it was nothing more than the draft of a plan, nothing but a dead letter, until life and validity were breathed into it by the voice of the people, speaking through their several State conventions» (Cuando el redactor entregó el texto no era más que un borrador de plan, nada más que letra muerta, hasta que se le insufló vida y validez, mediante la voz del pueblo, hablando a través de las diversas convenciones estatales) [vid. Gales and Seaton, Annals].

7 Vid. el amplio abanico de opiniones iniciales en Powell, H. J., «The Original Understanding of Original Intent», Harvard Law Review, 98 (1985), 885.

8 Los puritanos fueron un grupo protestante nacido en el siglo XVI y XVII, que intentaba «purificar» a la Iglesia de Inglaterra de lo que ellos consideraban prácticas católicas que dicha Iglesia habría conservado desde el cisma de Enrique VIII. 
la tradición reformada o calvinista. Dicha tradición se había inspirado en los reformadores del siglo XVI, Juan Calvino, Heinrich Bullinger y Martín Bucer, entre otros, y se había extendido a través de una parte de la primera Suiza moderna, de Francia, de los Países Bajos, de Escocia, de Alemania y de Inglaterra ${ }^{9}$. Los puritanos de Nueva Inglaterra habían refinado esta herencia calvinista europea con el esfuerzo de John Winthrop, John Cotton, Cotton Mather y otros, durante el siglo XVII. Habían matizado parte de su legado con los escritos de John Wise, Charles Chauncy y Jonathan Mayhew, entre otros, durante el siglo XVIII. Habían propagado sus ideas por la Norteamérica colonial mediante sus incansables publicaciones y, más adelante, mediante los escritos de sus correligionarios calvinistas, tales como los presbiterianos, los hugonotes y los reformados holandeses y alemanes, quienes se habían asentado en otras colonias, a lo largo de la costa atlántica. Sin embargo, fue en las colonias y estados de Nueva Inglaterra donde los puritanos tuvieron ocasión de transformar sus principios teológicos calvinistas en práctica constitucional.

Los puritanos que escribieron sobre libertad religiosa tenían especial interés en la naturaleza de la Iglesia y del Estado, así como en la relación entre ambos. Concebían la Iglesia y el Estado como dos asociaciones constituidas mediante sendos pactos, dos asientos de la autoridad de Dios, dentro de una comunidad más amplia, formada por un «pacto» 0 «acuerdo» que la fundaba. El pacto fundador de las comunidades puritanas, empezando por el Pacto del Mayflower, de 1620, establecía los ideales morales y religiosos básicos, de cada comunidad local. Las instituciones de Iglesia y Estado servían para llevar a la práctica estas ideas locales y comunitarias. Creían que cada una de dichas instituciones estaba revestida de un poder, de una forma de gobierno y de una misión que les eran propios. La Iglesia poseía el poder de la Palabra y estaba gobernada por autoridades pastorales, educativas y diaconales que colaboraban en la predicación de dicha Palabra, en la administración de los sacramentos, en la enseñanza a los jóvenes y en la atención a los pobres y necesitados. El Estado poseía el poder de la Espada y estaba gobernado por autoridades ejecutivas, legislativas y judiciales, llamadas a hacer cumplir la ley, castigar el delito, cultivar la virtud y proteger el orden público y la paz.

9 Para ejemplos de textos originarios, vid. Morgan, E. S. (ed.), Puritan..., op. cit., 2003 [1965]); Miller P. y Johnson, T. H. (eds.), The Puritans..., op. cit., rev. ed., 2 vols., 1963. 
En las comunidades de Nueva Inglaterra, donde prevalecían sus puntos de vista, los puritanos adoptaron una serie de normas orientadas a promover esta básica separación entre las instituciones y actividades de la Iglesia y del Estado. Quienes ostentaban autoridad dentro de la Iglesia tenían formalmente prohibido detentar cargos políticos, ser miembros de un jurado, interferir en cuestiones de gobierno, apoyar a candidatos políticos o censurar la conducta oficial de un gobernante. Por su parte, las autoridades civiles tenían prohibido ostentar cargos religiosos, interferir en el gobierno eclesial interno, llevar a cabo funciones sacerdotales propias del clero o censurar la conducta oficial de un clérigo. Permitir semejante intrusismo, por parte de las autoridades de la Iglesia o del Estado, aseveraba el Gobernador John Winthrop, «confundiría ambas jurisdicciones, que Cristo había querido distinguir» ${ }^{10}$.

No obstante, aunque Iglesia y Estado no habían de confundirse, sí debían permanecer $\ll$ cercanas y unidas ${ }^{11}$. Para los puritanos, estas dos instituciones estaban indisolublemente unidas en cuanto a su naturaleza y funciones. Cada una de ellas era un instrumento de la autoridad de Dios. Cada una contribuía a establecer y conservar la comunidad, así como sus ideales fundacionales, tanto morales como religiosos. Como afirmó el predicador puritano Urian Oakes, «considero esto como una pequeña maqueta del glorioso reino de Cristo en la tierra. Cristo reina entre nosotros sobre la comunidad política, así como sobre la Iglesia y tiene un glorioso interés en el bien de ambas sociedades, respectivamente $\gg^{12}$. Los puritanos, por tanto, consentían tanto en la coordinación como en la cooperación entre Iglesia y Estado.

Las autoridades civiles proporcionaban varias formas de ayuda material y moral a las congregaciones y a sus representantes. Algunas propiedades estatales eran donadas a colectivos religiosos para que sirvieran de lugares de reunión, casas parroquiales, escuelas, hospicios y orfanatos. Los recaudadores de impuestos recaudaban diezmos y contribuciones especiales para sostener a los ministros de

10 Citado por Breen, T., The Character of the Good Ruler (1970), 42, n. 24. Vid. otros ejemplos en FARRAND, M. (ed.), The Book of the General Laws and Liberties Concerning the Inhabitants of Massachusetts (1648) (1929), 18-20; «The Cambridge Synod and Platform (1648)», en The Creeds and Platforms of Congregationalism, Williston Walker (ed.) (1960), 234-37.

11 John Cotton, «Carta del Reverendo John Cotton to Lord Say and Seal» (1636), en Morgan, Puritan Political Ideas, 209-12.

12 Oakes, U., New England Pleaded with, and Pressed to Consider the Things Which Concern Her (1673), 49. 
la Iglesia congregacional, así como al ministerio realizado por ésta. Se concedían exenciones e inmunidades fiscales a las entidades religiosas, educativas y caritativas que dichos ministros dirigían. Se proporcionaban subvenciones especiales y protección militar a los misioneros y avanzadillas de carácter religioso. Normas penales especiales prohibían perturbar las ceremonias y propiedades religiosas. Las normas sobre festividades prohibían realizar cualquier forma de trabajo innecesario, o entregarse a un ocio zafio en domingo y en días festivos, así como requerían la presencia de los fieles en las ceremonias de culto.

Por su parte, las autoridades eclesiásticas proporcionaban al Estado diversas formas de ayuda material y moral. Los lugares de reunión de la Iglesia, así como las capillas, no se utilizaban sólo para la celebración de ceremonias religiosas, sino también para albergar asambleas municipales, mítines políticos y subastas públicas, alojar la escuela y la biblioteca comunitaria, así como para mantener el padrón municipal y los certificados de nacimiento, matrimonio y defunción. Las casas parroquiales no se usaban únicamente para alojar al ministro y a su familia, sino también para dar cobijo a huérfanos, viudas, enfermos, ancianos y víctimas de abusos y desastres naturales. Las autoridades eclesiales predicaban la obediencia a las autoridades civiles e imponían penas espirituales sobre los parroquianos culpables de algún crimen. Animaban a sus parroquianos a permanecer activos en los asuntos políticos y cada año pronunciaban un «sermón del día de las elecciones», sobre los principios políticos cristianos. Proporcionaban eruditas exposiciones sobre las exigencias de la Ley de Dios y, ocasionalmente, aconsejaban a los órganos legislativos y a los tribunales, especialmente sobre acaloradas cuestiones de moral pública y Derecho, tales como la pena de muerte.

Inicialmente, los líderes de Nueva Inglaterra ofrecieron pocas oportunidades para la experimentación religiosa individual o para el disenso. A pesar de su adhesión a una básica separación entre las funciones de la Iglesia y del Estado, las autoridades de Nueva Inglaterra impusieron un mismo calvinismo congregacionalista en cada comunidad local. Para dichas autoridades, la separación entre Iglesia y Estado no implicaba que la religión predominante dejara de ser la religión establecida oficialmente, ni tampoco implicaba tolerancia hacia otras religiones. Ya en los años treinta del siglo XVII, la joven colonia de la Bahía de Massachusetts había expulsado sumariamente a disidentes como Anne Hutchinson y Roger Williams ${ }^{13}$. Durante el siglo XVII, las restricciones

13 Hall, D. D., The Antinomian Controversy, 1636-1638, 2ª ed. (1968). 
a la inmigración, en la Bahía de Massachusetts y en otras colonias de Nueva Inglaterra, hacían pocas concesiones a católicos, judíos, «familiaristas, antinomistas y otros fanáticos», especialmente cuáqueros ${ }^{14}$. Leyes especiales, promulgadas a mediados del siglo XVII, prohibían la presencia de los cuáqueros y de sus enseñanzas en la colonia. Aquellos cuáqueros que habían llegado, o que se habían convertido recientemente, fueron expulsados. A quienes no se marchaban se les sometía a flagelación y se confiscaban sus propiedades. Cuatro cuáqueros que regresaron tras la expulsión fueron ahorcados en la plaza pública de Boston, entre 1659 y 1660.

A pesar de que los cuáqueros seguían sin ser bienvenidos, los baptis$\operatorname{tas}^{15}$, anglicanos y otros colectivos protestantes llegaron a ser tolerados en las colonias de Nueva Inglaterra, en parte como consecuencia del Acta de Tolerancia $(1689)^{16}$, aprobada por el Parlamento inglés, que exigía a todas las colonias apertura a los protestantes inconformistas ${ }^{17}$. Pese a ser tolerados, estos colectivos no puritanos carecían de cualquier derecho político o prestación social, pero sí estaban sujetos al pago de diversos diezmos y otras restricciones sobre sus propiedades y profesiones. En Massachusetts y en Connecticut, en especial, se introdujo un complejo sistema de impuestos religiosos: los diezmos eran recaudados por el Estado, pero éste permitía a cada contribuyente elegir la confesión religiosa que debía recibir lo recaudado. Sin embargo, sólo las Iglesias registradas y constituidas convenien-

14 Ward, N., The Simple Cobler of Aggawam in America, 5a ed. (1713), 43. La Familia Caritatis, también conocida como los «familistas» fue una secta religiosa mística fundada en Holanda hacia 1540 por Hendrik Niclaes y que, entre otras creencias, negaba el dogma de la Trinidad y el bautismo de niños. El antinomianismo era la doctrina por la cual la justificación por la fe y la gracia -típicamente protestante- excluía cualquier obligación de cumplir la ley moral. «Enthusiasts» (traducido aquí como «fanáticos») fue un término empleado en ocasiones en la Inglaterra de los siglos XVI y XVII para referirse peyorativamente a quien simplemente defendía una causa política o religiosa en público. Los cuáqueros (también conocidos como la «Religious society of friends») nacieron en Inglaterra, en el siglo XVII, como una escisión de la Iglesia de Inglaterra y abogaban por el sacerdocio de todos los cristianos y por una relación personal con Dios que excluía cualquier tipo de jerarquía religiosa $(n$. del t.).

15 Los baptistas son un colectivo protestante nacido en Holanda y en Inglaterra, en el siglo XVI, que rechazaban el bautismo de niños y sólo aceptaban el bautismo de creyentes adultos. En otras materias, seguían los principios protestantes clásicos de sola fide y sola scriptura.

16 En Stephenson, C. y Markham, F. B., Sources of English Constitutional History (edición revisada de 1972), 607-608.

17 En el ámbito anglosajón, reciben habitualmente el nombre de inconformistas («nonconformists») los miembros de Iglesias protestantes diferentes de la Iglesia oficial anglicana. Aunque no es exactamente lo mismo, también recibían el nombre de «dissenters» (n. del t.). 
temente podían ser elegidas como destinatarias de estos diezmos. Varios colectivos anglicanos, baptistas y evangélicos ${ }^{18}$ no pudieron constituirse $o$ no se constituyeron y, por ello, no pudieron ser escogidos para la recepción de lo recaudado con los diezmos. Más aún, sólo quienes podían probar su asistencia a la iglesia de modo rutinario disfrutaban del derecho a contribuir con sus diezmos a iglesias no oficialmente establecidas. Muchas personas no querían o no podían probar a las autoridades su asistencia regular a la iglesia y, ellos también, estaban imposibilitados para participar en este sistema. Este mecanismo persistió hasta las reformas constitucionales de Connecticut, en 1819, y de Massachusetts, en $1833^{19}$.

Con el transcurso del tiempo, la creciente presencia en Nueva Inglaterra de colectivos religiosos disidentes modificó lentamente la comprensión puritana de la libertad de conciencia. El calvinismo clásico enseñaba que cada persona era libre de establecer una alianza personal con Dios, inducido por Su irresistible gracia. Sin embargo, los puritanos del siglo XVII habían defendido una concepción estrecha e innegociable de dicha alianza. Los términos de la alianza estaban establecidos por Dios en la Biblia y cada cual era únicamente libre de aceptarlos o rechazarlos. Se puede observar tal modo de sentir en un panfleto de 1682 sobre «alianza y libertad», escrito por Samuel Willard, un prominente puritano de aquel entonces. Willard argumentaba que toda persona tiene «igual derecho», «título», «reivindicación», «libertad», y «prerrogativa» «de suscribir y disfrutar de cada bendición de la alianza». Sin embargo, para cuando Willard termina de enumerar todos los términos y cláusulas de la alianza, parecen ser sólo unos pocos los que son libres de suscribirla y escasa la libertad remanente, para los pocos que podrían hacerlo ${ }^{20}$.

Enfrentados a la realidad del pluralismo religioso, los escritores puritanos del siglo XVIII empezaron a ver la relación de alianza entre Dios y los hombres en términos más flexibles y voluntaristas. La alianza se hizo más permeable a elementos de otras confesiones cristianas y sus términos se abrieron

18 Los evangélicos («evangelicals») son una corriente religiosa presente en diversas confesiones protestantes, más que una Iglesia propiamente dicha. Su origen se suele situar en la década de 1730 y algunas de sus características más sobresalientes son la necesidad y la experiencia de la conversión («born again christians»), la centralidad de la Biblia y el proselitismo.

19 McLoughlin, W. G., New England Dissent, 1630-1833, 2 vols. (Cambridge, 1971).

20 Willard, S., Covenant-Keeping the Way to Blessedness (Boston,1682); ibid., Morality Not to Be Relied on for Life (1700); ibid., Walking with God (1701). 
más a la deliberación e innovación personal. Elisha Williams, el distinguido predicador puritano, jurista y rector de la universidad de Yale, explicó la cuestión de este modo, en 1744:

«Todo hombre tiene un mismo derecho a seguir los dictados de su propia conciencia, en asuntos de religión. Todo el mundo está sometido a una indispensable obligación de escrutar por su cuenta las Escrituras... y de hacer de ellas el mejor uso que pueda, para conocer la voluntad de Dios, la naturaleza y los deberes del Cristianismo. Y del mismo modo que todo cristiano está así obligado, así también posee el derecho inalienable de juzgar acerca de su sentido y significado y de seguir su juicio dondequiera que éste le lleve; un derecho incluso igual al de cualquier gobernante, ya sea civil o eclesiástico» ${ }^{21}$.

«La libertad religiosa es un derecho divino», escribió Israel Evans, predicador de New Hampshire, y «procede directamente del Ser Supremo, sin intervención de ninguna autoridad creada... [E]l Creador, en su inmensa sabiduría, no revistió a ninguna clase de hombres con el derecho de juzgar a sus semejantes en las grandes cuestiones de la religión $»^{22}$.

Sólo había un pequeño paso entre esta formulación y la más genérica y generosa garantía para la libertad religiosa, contenida en la Constitución de Massachusetts de 1780, redactada principalmente por John Adams, un puritano de pura cepa, que había decidido renunciar al púlpito, en favor de una carrera en la política y las leyes:

«Es el derecho, tanto como el deber de todos en sociedad, adorar públicamente y en los momentos previstos al Ser Supremo, el gran Creador y Conservador del universo. Y a ningún súbdito se le causará daño, se le molestará o constreñirá en su persona, libertad o bienes, por alabar a Dios en la manera y en el momento más acordes con los dictados de su propia conciencia o con la expresión de sus opiniones religiosas; siempre y cuando no altere la paz social u obstaculice a otros en su culto divino» ${ }^{23}$.

21 Williams, E., The Essential Rights and Liberties of Protestants (1744), 7-8. Algunos investigadores especulan con que el autor de este panfleto pudo ser Thomas Cushing.

22 Evans, I., «A Sermon Delivered at Concord, Before the Hon. General Court of the State of New Hampshire at the Annual Election (1791)», en Sandoz (ed.), Political Sermons, 1057, 1062-63.

23 Massachusetts Constitution (1780), Pt. I, Art. II; vid. también Vermont Constitution (1793). 
También fue natural que, como siguiente paso, se diera al pluralismo religioso carácter de virtud política, si no teológica. Zabdiel Adams expuso bien la opinión mayoritaria, en un sermón de 1782:

«En los modos y en las formas de religión; en los pareceres respecto a la doctrina, etc., se debe consentir a la gente, sin importunarla. Si la coerción llevara a la humanidad a una uniformidad de pareceres, nada ventajoso resultaría de ello. Es por el contrario óptimo que diferentes [confesiones] y denominaciones religiosas convivan en las mismas sociedades. Son freno y espía las unas para las otras y llegan a ser más escrupulosas con sus principios y prácticas... [D]onde los papistas y los protestantes viven juntos y entremezclados, ello sirve para mejorarlos a ambos... Con locos y fanáticos no puede haber ningún acuerdo, excepto entre gentes tan perturbadas como ellos. Pero incluso a éstos, cuando adoptan una actitud religiosa y no interrumpen la paz de la sociedad, el brazo de la ley no les debe molestar. [Sólo] aquella parte de la religión que tiene un efecto inmediato sobre el bien de la comunidad cae bajo las competencias del gobernante $\gg^{24}$.

\section{PeRSPECTIVAS EVANGÉLICAS}

La tradición evangélica norteamericana de libertad religiosa, en el siglo XVIII ${ }^{25}$, hunde sus raíces en el anabaptismo europeo del siglo XVI ${ }^{26}$. Esta corriente de la Reforma Protestante incluía originariamente a colectivos como los amish, huteritas, menonitas, baptistas, los hermanos moravos ${ }^{27}$ y otros. Ponían el acento en que la religión era una opción voluntaria, rubricada por el bautismo de adultos, y en que la Iglesia era una institución independiente,

24 ADAms, Z., «An Election Sermon (1782)», en Charles S. Hynemann y Donald S. Lutz (eds.), American Political Writing During the Founding Era, 1760-1805, 2 vols. (1983), 1:539, 556 (las mayúsculas y la cursiva del original han sido suprimidas).

25 Para los cambios en el significado del «Evangelismo», vid. Noll, M. A., «Evangelicals in the American Founding and Evangelical Political Mobilization Today», en James H. Hutson (ed.), Religion and the New Republic; Faith in the Founding of America (2000), 137.

$26 \mathrm{El}$ anabaptismo es una corriente protestante nacida en el siglo XVI, que propugnaba el bautismo consciente de adultos, así como una interpretación literal del Sermón de la Montaña, lo que les llevaba, en diferentes grados, a rechazar los juramentos, la violencia, los cargos públicos, etc. De esta corriente surgieron otras como los Amish, Menonitas o Huteritas ( $n$. del t.).

27 Los hermanos moravos (denominados oficialmente «Unitas Fratrum») proceden originalmente del movimiento reformista que Jan Hus lideró en Bohemia en el siglo XV. 
protegida del Estado por un «muro de separación». La tradición evangélica norteamericana hundía sus raíces en el «entusiasta experimento» de Rhode Island, que garantizó una «plena libertad en cuestiones religiosas» y no permitió el «establecimiento de una religión $»^{28}$. Los evangélicos encontraron poderosos aliados entre los cuáqueros, que habían iniciado su propio «experimento sacro» de libertad religiosa en Pennsylvania, en 1682, centrado en la libertad de conciencia y de práctica religiosa, así como en la separación entre Iglesia y Estado. Hacia mediados del siglo XVIII, los cuáqueros habían extendido sus particulares enseñanzas y prácticas por un buen número de las otras colonias y fueron campeones especialmente fogosos y elocuentes de la objeción de conciencia al servicio militar, a la obligación de prestar juramento, a los diezmos obligatorios y a la obligación de asistir al culto ${ }^{29}$.

Los evangélicos no emergieron como vigorosa fuerza política hasta después del «Gran Despertar» de 1720-178030, que aumentó radicalmente el número de sus miembros y expandió su mensaje. En el transcurso del último cuarto del siglo XVIII, y a lo largo de la costa atlántica, surgieron numerosos portavoces de la causa evangélica como Isaac Backus, John Leland, John Wesley, George Whitefield y una miríada de predicadores y autores de panfletos. El número de sus miembros creció exponencialmente hasta el punto de que, hacia 1820, superaba al de anglicanos y puritanos tradicionales. Se empezó a identificar a sus seguidores con numerosas etiquetas de carácter religioso: diversos tipos de baptistas y metodistas ${ }^{31}$, en su mayoría, pero también moravos, fanáticos («enthusiasts») y comunidades híbridas, como la Iglesia africana metodista episcopal. Estas etiquetas de tipo religioso apuntaban a veces a diferencias reales en cuanto al énfasis puesto sobre cuestiones teológicas por estos colectivos de la primera hora, que más tarde fraguarían

28 La frase está tomada del dirigente baptista, John Clarke, c. 1662, citado en ANDREws, Ch. M., The Colonial Period in American History, 2 vols. (1936), 2:42. Esta afirmación vuelve a aparecer en los Estatutos de Rhode Island, de 1663, que continuaron siendo su texto constitucional hasta 1843. Vid. ThORPe, Organic Laws, 6:3211.

29 Frost, J. W., A Perfect Freedom: Religious Liberty in Pennsylvania (1990); The Political Writings of William Penn, Andrew R. Murphy (ed.) (2002).

30 El término «Gran Despertar» («Great Awakening») suele hacer referencia a varios períodos, durante los siglos XVIII y XIX, en los que se intensificó el sentimiento religioso y el interés por la religión entre diferentes Iglesias protestantes, aunque fue liderado especialmente por ministros evangélicos (n. del t.).

31 Los metodistas son una escisión de la Iglesia anglicana, cuya doctrina procede de las enseñanzas de John Wesley. En general, rechazan la doctrina calvinista de la predestinación y hacen mucho hincapié en las obras de caridad (n. del t.). 
en amargos cismas y en diversas «denominaciones». No obstante, a pesar de las diferencias teológicas, en su conjunto, los primeros evangélicos norteamericanos coincidían en su insistencia sobre la libertad de conciencia, la prohibición de establecimiento oficial de una religión y la separación entre Iglesia y Estado. Aunque durante la época colonial, fuera de Rhode Island, los evangélicos tuvieron menos oportunidades que los puritanos, para institucionalizar sus puntos de vista, su infatigable predicación y sus publicaciones tuvieron una formidable influencia política en los comienzos del experimento norteamericano.

Como los puritanos, los evangélicos también hicieron propuestas teológicas y doctrinales sobre libertad religiosa. También ellos abogaron por la separación institucional entre Iglesia y Estado, la construcción de un «muro de separación entre el jardín de la Iglesia y la jungla del mundo», como Roger Williams lo expuso de modo célebre, en $1643^{32}$. No obstante, la mayor parte de los evangélicos fueron más lejos que los puritanos, llegando a disputarles los estados de Nueva Inglaterra, tanto en lo relativo a su definición de los derechos de los individuos y de los colectivos religiosos, como también en su insistencia sobre una más completa separación entre las instituciones de Iglesia y Estado. Los evangélicos buscaban proteger la libertad de conciencia de cada individuo y la libertad de asociación de cada colectivo religioso. Su método preferido para alcanzar estos objetivos fue la prohibición de otorgar cualquier carácter oficial a la religión y, en realidad, cualquier mezcla entre religión y política.

«La noción de comunidad política cristiana debe saltar por los aires para siempre», escribió John Leland, el fiero predicador baptista, que denunciaba tanto a la clase dirigente puritana como a la anglicana ${ }^{33}$. Resumiendo los típicos pareceres evangélicos, Leland denostaba cualquier establecimiento oficial de una religión como algo «malvado», ya fuera la declaración de Constantino sobre la cristiandad trinitaria, la imposición del Islam como religión oficial en el Imperio Otomano, la del catolicismo en España, del anglicanismo en Inglaterra, o del puritanismo en Nueva Inglaterra. El establecimiento oficial de una religión es algo malvado, argumentaba Leland, primero porque cuando «hombres falibles y faltos de inspiración hacen de sus propias opiniones un criterio de ortodoxia», la religión se atrofia y se vuelve pedante, «la ignorancia

32 Williams, Complete Writings, 1:392.

33 The Writings of the Late Elder Fohn Leland (1845), 118. 
y la superstición prevalecen, o la persecución arrasa». En segundo lugar, el establecimiento oficial de una religión es algo malvado porque «las mentes de los hombres tienen el prejuicio de abrazar aquella religión favorecida y mimada por la ley y con ello se alimenta la hipocresía». En tercer lugar, «el establecimiento oficial de una religión no sólo sustrae y aliena los afectos de unos por otros», sino que mantiene alejados o aleja del Estado a los inconformistas, llevándose consigo su lealtad, trabajo e impuestos y dejando que las religiones apagadas y anémicas se propaguen o conviertan a otros por la fuerza. En cuarto lugar, «el establecimiento oficial de una religión troca a la Iglesia en criatura terrenal y a la religión en un principio de gobierno, lo cual tiende naturalmente a que los hombres concluyan que la religión no es más que una engañifa del Estado». En quinto lugar, incluso en los así llamados países cristianos, «no hay dos reinos o Estados que establezcan el mismo credo o las mismas formas en materia de fe». Esto conduce a vecinos y a familias a conflictos y guerras inevitables, como la historia europea ha demostrado con demasiada frecuencia. En sexto lugar, el establecimiento oficial de una religión sirve simplemente para ocultar las inseguridades y dudas de las autoridades eclesiásticas. En vez de tener fe en la contundencia de sus pareceres, «mandan a los demás» y revelan una «excesiva simpatía por un sistema particular» que se convierte en su propio ídolo teológico. Finalmente, el establecimiento oficial de una religión también encubre la inseguridad de los políticos. «Los gobernantes temen con frecuencia que si permiten a cada hombre pensar, hablar y practicar el culto como quieran, el edificio entero del Estado perecerá, a causa de su diversidad $\gg^{34}$.

En lugar de establecer oficialmente una religión, los evangélicos hacían énfasis en el voluntarismo religioso: la libertad de cada individuo de elegir, rechazar o cambiar de religión. «La verdadera religiosidad no puede ser sino una voluntaria obediencia a la voluntad revelada [de Dios]», declaró Isaac Backus, la principal lumbrera baptista del siglo XVIII ${ }^{35}$. Dios llamó a los individuos adultos a hacer una elección consciente, aceptando así la fe a través del bautismo de adultos. La coerción estatal o el control de sus elecciones -tanto directamente, a través de la persecución y la represión o indirectamente, mediante

34 LeLAND, J., «The Rights of Conscience Inalienable», en The Writings of fobn Leland, L.F. Greene (ed.) (1969), 179-92.

35 BACKUS, I., «A Declaration of the Rights, of the Inhabitants of the State of Massachusetts-Bay in New England (1779)», en William G. McLoughlin (ed.), Isaac Backus on Church, State, and Calvinism: Pamphlets, 1754-1789 (1968), 487. 
la denegación de derechos civiles o de beneficios sociales a quienes realizaran dicha elección- es una ofensa, tanto contra el individuo como contra Dios. En la comunidad debían coexistir una pluralidad de religiones. A Dios, no al Estado, le competía decidir qué religiones debían prosperar y cuáles debían decaer.

En lugar de la protección y del patronazgo estatales hacia la religión, los evangélicos exigían autonomía para que los colectivos religiosos se autogobernaran. Cada comunidad religiosa, argumentaban los evangélicos, debía verse libre del control estatal sobre sus miembros y sobre su culto, de la regulación estatal de sus propiedades y sobre su forma de administración interna, de la obligación legal de registrar a sus miembros y a su clero, de la interferencia estatal en su disciplina y gobierno y de la recaudación estatal de los diezmos e impuestos religiosos. «Soy tan consciente de la importancia de la religión y de su utilidad para la sociedad humana» como lo son los puritanos, escribió Backus. $\ll$ Y coindido con [ellos] en que el temor y la reverencia a Dios y los terrores de la eternidad son las más poderosas riendas en las mentes de los hombres. Sin embargo, estoy muy alejado de su posición en cuanto a pensar que tales riendas se romperán si se instaura la igualdad religiosa». Considérese la larga historia del carácter oficial del cristianismo, donde se han consentido tales formas de intrusión estatal en los colectivos religiosos. Tal carácter oficial nunca condujo a la pureza de la religión, afirmó Backus sino que, en vez de eso, «se introdujeron y se practicaron la tiranía, la simonía y el robo, bajo el nombre de cristianismo». Considérense ahora las comunidades sin religiones oficialmente establecidas: en ellas florecen sin medida la religión, el Estado y la sociedad. Y establézcase un paralelismo con los principios de la revolución norteamericana: «Toda América se había alzado en armas» contra la fiscalidad sin representatividad. Pero del mismo modo que los americanos no estaban representados en el Parlamento Británico, tampoco los disidentes religiosos estaban representados entre las autoridades civiles, en un Estado confesional. Y sin embargo los inconformistas estaban sujetos a los impuestos religiosos y a la normativa estatal en materia de religión. Finalmente, Backus urgía a considerar principios bíblicos:

«Dios ha armado expresamente al magistrado con la espada para castigar a quienes hacen mal a sus vecinos, y su devoción a esa tarea y nuestra obediencia a tal autoridad es impuesta [por la Biblia]. Pero es evidente que la espada está excluida del reino del Redentor... [E]s imposible mezclar Iglesia y Estado sin violar los mandamientos que nuestro Señor dirige a ambos. Su 
mandamiento a la Iglesia es: apartad de entre vosotros al malvado. Su mandamiento al Estado es: permite a ambos que crezcan juntos hasta la siega. Pero parece que, durante estos mil años, la pura disciplina eclesial del Evangelio no ha tenido apenas lugar, allí donde ha habido religiones oficialmente establecidas por el Estado» ${ }^{36}$.

Algunos evangélicos empleaban el principio de la autonomía de la Iglesia y de la prohibición de establecimiento, a fin de oponerse al apoyo estatal a la religión, en forma de exenciones fiscales, inmunidades de jurisdicción o donaciones de tierras. Tales evangélicos temían el patronazgo estatal de las Iglesias casi tanto como temían la represión estatal. Aquellos colectivos religiosos que recibieran beneficios del Estado se encontrarían inevitablemente en deuda con el Estado, dependerían de su generosidad y se distraerían de sus mandatos divinos. «Si los gobernantes civiles se alejan tanto de su ámbito como para tomar sobre sí el cuidado y administración de los asuntos religiosos», rezaba una Declaración baptista de 1776, «adiós a la libre práctica de la Religión» ${ }^{37}$.

La principal preocupación de los evangélicos era teológica, no política. Tras haber sufrido como minorías religiosas durante más de un siglo, en la Norteamérica colonial, y durante más de dos siglos en Europa, los evangélicos buscaban una herramienta constitucional para liberar a toda religión de los grilletes de la ley y para aliviar a toda confesión de las restricciones del Estado. Al hacerlo así, la mayor parte de los evangélicos de la época fundacional -excepto Isaac Backus, que se basaba en su héroe del siglo XVII, Roger Williamsdesarrollaron sólo los rudimentos de una teoría política ${ }^{38}$. La mayor parte de los evangélicos se contentaban con un Estado que creara un clima conducente al cultivo de una pluralidad de religiones y que diera cabida a todos los creyentes y colectivos religiosos, sin condicionamientos ni controles.

36 Ibid., 351, 357-58, 373-75 (énfasis omitido).

37 «Declaration of the Virginia Association of Baptists (diciembre 25, 1776)», en The Papers of Thomas Fefferson, Julian P. Boyd (ed.) (1950), 1:660-661.

38 Backus y algunos otros evangélicos que sí hacían propuestas políticas tendían a estar de acuerdo con los puritanos y con los cívico-republicanos en que los cargos públicos sólo debían ser ocupados por cristianos y en que el estado tenía un papel que jugar en el cultivo de la moral pública, mediante normas contra la blasfemia, la asistencia a espectáculos públicos, los juegos de naipes y las infracciones del descanso dominical. Vid. McLoughlin, W. G., Soul Liberty: The Baptists' Struggle in New England, 1630-1833 (1991), 194-95, 267-68. 


\section{PERSPECTIVAS ILUSTRADAS}

El movimiento ilustrado en Norteamérica proporcionó una teoría política que complementaba la teología evangélica sobre libertad religiosa. La Ilustración no fue un pensamiento único y compacto, sino una serie de movimientos intelectuales diversos, que abarcaron múltiples disciplinas académicas y círculos sociales, a través de Europa y Norteamérica. Entre sus más destacados exponentes se encontraban Montesquieu, Condorcet y Voltaire en Francia, junto a John Locke, Adam Smith y David Hume en Inglaterra y Escocia. Entre sus principales representantes en Norteamérica se encontraban Thomas Jefferson y Thomas Paine, apoyados en algunas causas por Benjamin Franklin y James Madison ${ }^{39}$. Fue especialmente la Revolución Norteamericana la que inspiró a estas personalidades norteamericanas a convertir los ideales de la Ilustración en imperativos constitucionales.

Los escritos del filósofo y teólogo inglés John Locke inspiraron en gran medida este movimiento. En su famosa Carta sobre la Tolerancia (1689), Locke había destilado las enseñanzas liberales inglesas y holandesas del siglo XVII en una elegante súplica para que Iglesia y Estado pusieran fin a sus corrosivas alianzas y destructivas limitaciones de la libertad de conciencia. «Por encima de todo», defendía Locke, es «necesario distinguir con exactitud entre los asuntos del gobierno civil y los de la religión y acordar los justos límites que yacen entre uno y otro». La Iglesia, escribió, debe estar «absolutamente separada y distinguida de la sociedad civil», porque la Iglesia es, simplemente, «una voluntaria sociedad de hombres, que se unen por propia voluntad, en orden a [practicar] el culto público a Dios, de la manera que juzgan que a Él le es aceptable y eficaz para la salvación de sus almas». Los miembros de la Iglesia son libres de acceder y libres de salir de esta sociedad. Son libres de determinar su orden y organización y de ordenar su disciplina y culto, del modo que consideren más conducente a la vida eterna. «En esta sociedad no debería ni puede tratarse de nada de lo que atañe a la posesión del poder civil y mundano. Ninguna violencia debería emplearse en ocasión alguna. Ya que la violencia pertenece totalmente al magistrado civil» ${ }^{40}$.

39 MaY, H., The Enlightenment in America, Oxford University Press, New York, 1976.

40 LocKe, J., Letter Concerning Toleration (1689), en The Works of John Locke, $12^{\mathrm{a}}$ ed., 9 vols. (1824), 5:1-58, en 9,13,16,21. Locke escribió dos cartas posteriores similares y, en el momento de su muerte, en 1704, tenía a medias una cuarta carta. La primera carta, de 1689, fue la más conocida en Norteamérica. 
Por su parte, el poder del Estado no puede tocar a la religión, argumentaba Locke. El Estado no existe más que para proteger a las personas en sus vidas externas, en su disfrute de la vida, libertad y propiedad. «La verdadera y salvífica religión consiste en la persuasión interna de la mente», que sólo Dios puede tocar y cuidar. Una persona no puede ser compelida a creer en la verdad de algo mediante la fuerza externa, ni mediante la «confiscación de propiedades, encarcelamientos, [o] tormentos», ni mediante el cumplimiento forzoso de «artículos de fe o formas de culto», establecidos por ley. «Y es que las leyes no tienen fuerza sin penas, y las penas en este caso son absolutamente impertinentes, porque no son apropiadas para convencer a la mente». «Son solamente la luz y las pruebas, las que pueden operar un cambio en las opiniones [religiosas] de los hombres: luz que no puede proceder de ninguna manera de los sufrimientos corporales, ni de ningún otro tipo de penas externas», infligidas por el Estado. Cada persona «tiene la suprema y absoluta autoridad de juzgar por sí mismo» en materia de $\mathrm{fe}^{41}$.

Locke no quiso llevar esta tesis a radicales conclusiones de carácter laicista. Su Carta sobre la Tolerancia presupone un poder político y una comunidad comprometidas con un Cristianismo común. Creía que las leyes estatales que se orientaran al bien común, sólo rara vez «aparecerían como ilegítimas a la conciencia de la persona individual» y sólo rara vez entrarían en conflicto con las creencias y prácticas cristianas convencionales. Los católicos, musulmanes y otros creyentes «que se entregan al servicio y protección de otro príncipe», sobran en esta comunidad civil. Más aún, «no se ha de tolerar de ninguna manera a quienes niegan la existencia de un Dios», ya que «las promesas, alianzas y juramentos, que son los vínculos de la sociedad humana, no tienen ninguna influencia sobre un ateo» ${ }^{42}$. Locke reforzó estas aseveraciones en sus escritos de carácter teológico, argumentando a favor de la contundencia de la simple ley natural bíblica, en obras como La razonabilidad del cristianismo (The Reasonableness of Christianity), Ensayos sobre la ley de la naturaleza (Essays on the Law of Nature), y Pensamientos sobre la educación (Thoughts on Education), así como respaldando la utilidad de un moderado republicanismo cristiano, en sus comentarios a varios libros del Nuevo Testamento ${ }^{43}$.

41 Ibid., $11,41$.

42 Ibid., 47.

43 Locke, J., The Reasonableness of Christianity, en ibid., Works, 6:1-158, at 140-143; ibid., Essays on the Law of Nature, W. von Leyden (ed.), Clarendon Press, Oxford 2002 [ca. 1662]; The Educational Writings of John Locke, J., Axtell (ed.), Cambridge University Press, Cambridge 1968. Vid. 
Un siglo después y a un océano de distancia, los escritores de la Ilustración norteamericana llevaron aún más lejos la teoría de Locke sobre la tolerancia religiosa, conduciéndola a formas legales y políticas más tangibles ${ }^{44}$. Los escritores norteamericanos marcharon, más allá de la mera tolerancia, hacia una más robusta libertad de conciencia y de culto, para todos los amantes de la paz. Como lo expresó Thomas Paine: «la tolerancia no es lo opuesto de la intolerancia, sino su falsificación. Ambos son despotismos. Una de ellas se arroga el derecho de restringir la libertad de conciencia, y la otra el de concederlo» ${ }^{45}$. Lo que se necesitaba en cambio era un sistema jurídico y político que otorgara libertad total a cualquier religión pacífica y que denegara todo privilegio político a cualquier religión en particular.

El Estado, pensaban los escritores de la Ilustración, no debería prestar una especial ayuda, apoyo, privilegio o protección a doctrinas o a colectivos religiosos mediante asignaciones fiscales, ni mediante la recaudación de diezmos, donaciones especiales de bienes o inmuebles, leyes especiales sobre registro de entidades, o especiales normas penales contra la blasfemia, el sacrilegio y la violación del sabbat. El Estado no debería sustentar sus leyes sobre bases exclusivamente religiosas, ni dirigirlas hacia fines exclusivamente religiosos. El Estado no debería ni aprovecharse de los servicios de las autoridades eclesiales para cumplir con sus tareas políticas, ni tampoco interferir en la administración, organización, u ortodoxia de los colectivos religiosos. Como lo expuso Madison, en 1822: «Una perfecta separación entre las cuestiones eclesiásticas y civiles» es el mejor camino, ya que «la religión y el Estado existirán ambos con mayor pureza, cuanto menos estén mezclados el uno con el otro» ${ }^{46}$.

Waldron, W., God, Locke, and Equality: Christian Foundations of John Locke's Political Thought, Cambridge University Press, Cambridge, 2002; Perry, J., The Pretenses of Loyalty: Locke, Liberal Theory, and American Political Theology, Oxford University Press, Oxford, 2011.

44 Por ejemplo, Jefferson introdujo un buen número de ideas de la Letter Concerning Toleration, de John Locke, en su «Bill for the Establishment of Religious Freedom» (1779). Vid. sus «Notes on Locke and Shaftesbury», en The Papers of Thomas Fefferson, 1:544-51. Vid. KEsSLER, S., «Locke's Influence on Jefferson's 'Bill for Establishing Religious Freedom'», Fournal of Church and State, 25 (1983), 231.

45 PaIne, T., The Rights of Man, parte 1, en Philip Kurland and Ralph Lerner (eds.), The Founders' Constitution, 5 vols. (1987), 5:95-96.

46 Carta a Edward Livingston (July 10, 1822), en The Writings of James Madison, G. Hunt (ed.), G. P. Putman's Sons, New York, (1900-1910), 9:98, 102. 
$\mathrm{Al}$ igual que Locke, Madison no llevó esta lógica hasta el extremo, en especial en lo relativo a todo aquello que no era esencial, en las relaciones Iglesia-Estado. En una carta de 1833 y dirigida a Jasper Adams, escribió:

«Puede que no sea fácil, en todos los casos, trazar una línea divisoria entre los derechos de la religión y los de la autoridad civil, con la nitidez necesaria para evitar colisiones y dudas sobre cuestiones secundarias. La mejor manera de protegerse contra la tendencia a la usurpación por parte de uno u otro, o contra la corrupta coalición o alianza entre ambos, será mediante una total abstinencia del Estado, en lo relativo a cualquier tipo de interferencias, más allá de la necesidad de preservar el orden público y de proteger a cada secta contra las transgresiones de sus derechos legales, por parte de las otras ${ }^{47}$.

Tales posturas se basaban tanto en el escepticismo hacia la religión organizada, como en el miedo a un Estado autocrático. Se pensaba que permitir que Iglesia y Estado se vieran libres de toda restricción sería una invitación al abuso y a la arbitrariedad. Permitir que se aliaran sería desventajoso para ambas y produciría, en palabras de Paine, «cierto tipo de animal similar al mulo, capaz sólo de destruir, pero no de procrear $\gg^{48}$. Thomas Jefferson manifestó una oposición particularmente estridente a la religión organizada, en especial respecto al Cristianismo Trinitario. Tal y como dijo en una carta privada a John Adams:

«Es demasiado tarde para que los hombres sinceros pretendan que creen en misticismos platónicos como que tres son uno y uno son tres; y en que a pesar de ello el uno no es tres y los tres no son uno... Tal es el arte, el poder, el negocio de los sacerdotes. Si echamos a un lado las delicadas telas de araña de las religiones traicioneras, ya no atraparán más moscas. Por ello, todos deberíamos, como hacen los cuáqueros, vivir sin un orden sacerdotal, predicar nosotros mismos, seguir el oráculo de nuestra conciencia y no decir nada sobre lo que nadie puede comprender, ni por tanto creer; porque yo entiendo que la creencia es el asentimiento de la mente frente a una proposición inteligible ${ }^{49}$.

47 Madison, J., «Carta al Reverendo Adams» (1833), en DreisbaCh, D., Religion and Politics in the Early Republic, University Press of Kentucky, Lexington, KY, 1996, 120.

48 PaIne, Th., «The Rights of Man» (1791), en The Complete Writings of Thomas Paine, P. S. Foner (ed.), 2 vols., The Citadel Press, New York (1945), 1:243-462, at 292.

49 Carta a John Adams (August 22, 1813), en The Works of Thomas Jefferson, 12 vols., P. L. Ford (ed.), G. P. Putnam's Sons New York and London, 1905, 11:328-31. 
Tales pareceres se basaban también en la asunción de que la persona es fundamentalmente un ser individual y de que la religión es primordialmente una cuestión de razón y conciencia privadas y sólo de modo secundario una cuestión de asociación comunitaria y asentimiento colectivo. «Mi propia mente es mi propia Iglesia», escribió Paine ${ }^{50}$. Toda persona, afirmó Madison, tiene el derecho de formarse «una opinión racional» acerca de «el deber que adeuda al Creador y la manera en que tal deber ha de cumplirse ${ }^{51}$. La cuestión de si los deberes religiosos habían de cumplirse individual o corporativamente era de importancia secundaria ${ }^{52}$.

Estas opiniones también se basaban en una visión contractualista de la sociedad. Los ilustrados veían la religión como uno de los derechos naturales e inalienables que Dios había otorgado a cada uno, al nacer. Ni el Estado ni la Iglesia podían abolir este derecho natural a la religión, y nadie podía ceder este derecho a otro. Al contrario, Estado e Iglesia podían tan solo, mediante sus acuerdos fundacionales, establecer las condiciones apropiadas para el ejercicio de este derecho natural, en sus respectivas sociedades. Como ciudadanos del Estado, todos tienen una absoluta libertad de práctica de su religión, con el límite de la violación de los derechos de su vecino o el orden público. El Estado puede intervenir únicamente si la práctica religiosa de una persona viola estas condiciones previas y, en ese caso, sólo porque tal persona ha violado los términos básicos del contrato social. En tanto que fieles, todas las personas tienen el derecho y el deber de practicar la religión conforme a las normas y rituales de la Iglesia a la que se unieron voluntariamente. La Iglesia puede insistir en el cumplimiento de sus normas y rituales y el Estado no puede interferir en tales decisiones internas de carácter eclesial. Sin embargo, la Iglesia no tiene poder para forzar la conciencia de sus miembros, poner obstáculos a quienes quieran abandonarla o violar sus derechos a la vida, a la integridad física o a la propiedad; cuando lo haga, el Estado debe intervenir para proteger a dichos miembros, que continúan siendo ciudadanos, ya que la Iglesia disfruta sólo

50 PaIne, Th., Age of Reason, 1, en ID., Collected Writings, E. Foner (ed.), The Library of America, New York (1995), 666.

51 MADISON, «Memorial and Remonstrance», sec. 1.

52 En sus «Detached Memoranda» of c. 1817, Madison subrayó su desagrado hacia las religiones e iglesias organizadas, mediante la crítica a las normas que permitían a las entidades religiosas adquirir personalidad jurídica, estar exentas del pago de impuestos, acumular propiedades y aumentar su poder político mediante los capellanes de las instituciones legislativas, entre otros medios. Vid. FleET, E., «Madison's 'Detached Memoranda'», William and Mary Quarterly, $3^{\text {a }}$ serie, 3 (1946), 534, 554. 
de aquellos poderes y derechos que sus miembros le concedieron mediante el contrato fundacional eclesial. Ningún miembro puede conceder a la Iglesia derechos sobre la conciencia (que pertenece a Dios) o sobre el derecho a la vida, la integridad física y la propiedad (en las que sólo el Estado puede inmiscuirse, siempre conforme al principio de tutela judicial efectiva).

La Virginia post-revolucionaria demostró ser terreno fértil para que los mayores exponentes políticos de la tradición ilustrada pusieran por obra sus ideas $^{53}$. La Declaración de Derechos de Virginia de 1776 daba comienzo con una famosa declaración: «Que todos los hombres son por naturaleza igualmente libres e independientes y tienen ciertos derechos esenciales, de los cuales, cuando se organizan en sociedad, no pueden, por medio de ningún acuerdo, privar o despojar a su progenie; en concreto, el disfrute de la vida y la libertad, con los medios de adquirir y poseer propiedad y de buscar y lograr la felicidad y seguridad». La libertad religiosa era uno de estos «derechos esenciales», cuyo ejercicio pleno y libre se consideraba básico para «lograr la felicidad». El artículo 16 de la Declaración de Derechos, al que Madison dio forma, establecía:

«Que la religión, o el deber que adeudamos a nuestro Creador y la manera de cumplirlo, sólo pueden ser dirigidos por la razón y la convicción, no por la fuerza o la violencia; $y$ por lo tanto, todos los hombres tienen derecho, en la misma medida, a practicar libremente la religión, conforme a los dictados de su conciencia; y que es deber mutuo de todos el practicar la cristiana paciencia, el amor y la caridad, unos hacia otros».

El artículo 15 de la Declaración de Derechos profundizaba en esta comprensión de los deberes mutuos: «Que ningún pueblo conseguirá preservar un gobierno libre, ni tampoco las bendiciones de la libertad, sino mediante una firme adhesión a la justicia, la moderación, la temperancia, la frugalidad y la virtud y un empleo constante de los principios fundamentales ${ }^{54}$.

Los artículos 15 y 16 de la Declaración de Derechos de Virginia fueron una de las más influyentes formulaciones del derecho a la libertad religiosa en la joven república y muchos otros textos constitucionales y debates parlamentarios iniciales se hicieron eco de ellos. Su atractivo residía, en parte, en

\footnotetext{
53 BuCKLEY, T. E., Church and State in Revolutionary Virginia, 1776-1787, University Press of Virginia, Charlottesville, 1977.

54 Madison, Papers, 1:175.
} 
su inteligente combinación de acentos ilustrados y evangélicos relativos a la libertad de conciencia, libertad de práctica e igualdad de creencias, junto con el énfasis que el republicanismo cívico y el cristianismo tradicional ponían en un Dios «creador»y en los deberes mutuos de todos de practicar la «cristiana paciencia, el amor y la caridad», así como otras virtudes, hacia los demás. Esta combinación de diversas fuentes de inspiración fue clave para la pronta aceptación del texto, en un estado cuya tradicional élite anglicana estaba perdiendo puestos ante el creciente número de evangélicos y presbiterianos, entre otros. Esto también explica su eventual y expansivo atractivo entre el resto de estados de la Unión.

La famosa ley de Virginia, denominada con razón «Ley para el establecimiento de la libertad religiosa», redactada por Thomas Jefferon en 1779 y aprobada en 1786, contaba con una terminología más abiertamente ilustrada. La ley comenzaba celebrando que «Dios todopoderoso ha creado la mente libre, de manera que cualquier intento de influir en ella mediante castigos temporales, cargas o sanciones civiles, no producen más que hábitos de hipocresía y crueldad y nos alejan del plan del Autor sagrado de nuestra religión». La ley repasaba la devastación provocada por la represión religiosa y el establecimiento oficial de la religión, así como las resultantes ofensas a Dios, la religión, las Iglesias, los Estados y los individuos. A continuación garantizaba:

«Que no se obligará a nadie a participar o apoyar ningún tipo de culto, templo o ministerio religioso, ni se obligará o se obstaculizará, molestará o se impondrán a nadie cargas sobre su cuerpo o sus bienes, ni de otro modo sufrirá nadie con motivo de sus opiniones o creencias religiosas; sino que todo el mundo será libre de profesar y defender con argumentos sus opiniones en materia de religión y ello no disminuirá, aumentará o afectará de ninguna manera sus facultades civiles ${ }^{55}$.

Estas nobles salvaguardias de los derechos religiosos individuales iban acompañadas de vigorosas restricciones sobre los derechos de los colectivos religiosos, restricciones por las que también abogaban ciertos exponentes de la Ilustración. Antes de que comenzara el siglo XIX, el poder legislativo de Virginia había prohibido que las entidades religiosas tuvieran personalidad ju-

55 Statutes at Large of Virginia, 12:84-86. 
rídica, prohibición que todavía perdura hoy en día en Virginia Occidental. No obstante, el Estado de Virginia reformó recientemente su constitución estatal, después de que un tribunal federal entendiera que dicha prohibición infringía el derecho a la libre práctica ${ }^{56}$.

\section{PerspeCtivas CÍVICO-REPUBLICANAS}

Del mismo modo que el movimiento ilustrado proporcionaba una teoría política que servía de complemento a la teología evangélica sobre libertad religiosa, así también el movimiento cívico-republicano proporcionaba una robusta filosofía política que complementaba la teología puritana sobre libertad religiosa. Los mismos cívico-republicanos eran un ecléctico grupo de políticos, predicadores y autores de panfletos que se esforzaban por cultivar un conjunto de valores y creencias comunes en la nueva nación ${ }^{57}$. Sus principales portavoces incluían a George Washington, John Adams, Benjamin Rush, John Jay, Oliver Ellsworth y Samuel Adams, entre otros. Este movimiento encontró también un apoyo considerable entre los intelectuales laicos piadosos de la nueva república. Mientras que muchas de las ideas madre de este movimiento estaban ancladas en anteriores ideales anglicanos y puritanos sobre la comunidad cristiana llamada a dar gloria a Dios, los cívico-republicanos exponían estas ideas de un modo más genérico y utilitario, como un argumento sobre el lugar y utilidad básicos que debían tener todas las religiones pacíficas, en una sociedad bien gobernada.

A pesar de que, a finales del siglo XVIII, los líderes cívico-republicanos habían encontrado en los puritanos sus aliados teológicos naturales, seguían teniendo mucho en común con los mayores exponentes evangélicos e ilustrados. También ellos abogaban por una libertad de conciencia para todos y porque el Estado apoyara la existencia de una pluralidad de religiones, dentro de la comunidad política. También ellos se oponían a aquellas intrusiones de la religión en la política que alcanzaban el nivel de la teocracia, así como a

56 Constitución del estado de West Virginia, Art. IV, Sec. 47; Constitución de Virginia, Art. IV, Sec. 14 (la reforma entró en vigor el 1 de enero de 2007). Vid. también Falwell v. Miller, 203 F.Supp. 2d 624 (W.D. Va. 2002) (anulando una previa disposición de Virginia).

57 Hatch, N. O., The Sacred Cause of Liberty (1977); Wood, G. S., The Creation of the American Republic, 1776-1787 (1969). RaHE, P., Republics Ancient and Modern (1992); Catherine L. Albanese, Sons of the Fathers: The Civil Religion of the American Revolution (1976). 
aquellas intrusiones políticas en la religión que alcanzaban el nivel de establecimiento oficial de una religión. En especial a nivel nacional, era esencial asegurar una plena libertad religiosa para todos. George Washington lo expuso con firmeza en una carta de 1770, dirigida a la comunidad hebrea de Newport, en Rhode Island:

«Los ciudadanos de los Estados Unidos de América pueden congratularse por haber dado a la humanidad ejemplos de política generosa y liberal; una política que merece la pena imitar. Todos poseen por igual la libertad de conciencia y los privilegios de la ciudadanía. Ya no se habla de tolerancia, como cuando una clase de personas disfrutaba del ejercicio de sus inherentes derechos naturales, gracias a la generosidad de otra clase. Y esto porque, felizmente, el Gobierno de los Estados Unidos, que no aprueba la intolerancia y no contribuye a la persecución, solamente exige a quienes viven bajo su protección que se conduzcan como buenos ciudadanos, prestando en todo momento su apoyo efectivo $»^{58}$.

Sin embargo, al contrario que los escritores evangélicos e ilustrados, pero del mismo modo que los escritores puritanos, los escritores cívico-republicanos buscaban impregnar la esfera pública de una ética religiosa y de unos valores comunes, aunque menos confesionales y teológicamente consecuentes que los propugnados por los puritanos. Una de las claves de este modo de pensar cívico-republicano era que la religión, y en particular el cristianismo, era básico para la prosperidad y felicidad de los ciudadanos, así como para la eficacia y eficiencia del buen gobierno ${ }^{59}$.

«La religión y la moralidad son los pilares esenciales de la sociedad civil», declaró Washington. «La religión y la moralidad son apoyos indispensables de todas las inclinaciones y hábitos que conducen a la prosperidad política ${ }^{60} . \ll$ No existe ningún gobierno», clamaba John Adams, «armado con

58 Carta a la Congregación Judía de Newport, Rhode Island (August 18, 1790), en The Papers of George Washington, W.W. Abbot et al. (eds.) (1987), 6:285.

59 Vid. ejemplos en Hutson, J. H., Forgotten Features of the Founding: The Recovery of Religious Themes in the Early American Republic, Rowman \& Litlefield, Lanham, Md., 2003, 1-44; MCCoNNELL, M. W., «Establishment and Disestablishment at the Founding: Part I: Establishment of Religion», William and Mary Law Review, 44 (2003), 2105, 2181y ss.

$60 \ll$ Letter to the Clergy of Philadelphia (March 3, 1797)», en The Writings of George Washington from the Original Manuscript Sources, 1745-1799, J. C. Fitzpatrick (ed.), 39 vols. U.S. Govt. Print. Washington,1931, 35:416; ID., Discurso de Despedida (September 17, 1796), en ibid., $35: 214,229$. 
poder suficiente como para enfrentarse a las pasiones humanas que no estén embridadas por la moralidad y la religión ${ }^{61}$. «La religión y la libertad son el pan nuestro de cada día, en la comunidad política», escribió el rector de Yale, Timothy Dwight ${ }^{62}$. Los cívico-republicanos insistían en que la sociedad necesita un trasfondo de valores y creencias religiosas y un cuerpo de ideas e ideales cívicos que fueran llevados a la práctica, tanto mediante el Derecho como mediante la presión de la comunidad. Esto fue lo que Benjamin Franklin había llamado, en 1749, la «religión pública» (y lo que Robert Bellah llamaría más tarde la «religión civil») de Estados Unidos, que cimentaba la existencia de una pluralidad de colectivos religiosos ${ }^{63}$. En esta «Religión pública» se predicaba un credo de honestidad, diligencia, devoción, servicio público, patriotismo y obediencia, amor a Dios, buena vecindad y autoestima, así como otros tópicos de carácter ético que, en el momento de la fundación del país, formaban parte de las enseñanzas de diversas tradiciones religiosas. Sus iconos eran la Biblia, la Declaración de Independencia, las «campanas de la libertad» y la Constitución. Su clero eran ministros con espíritu de servicio público y políticos devotos. Su liturgia eran oraciones, himnos y sermones, así como las ofrendas del Día de Acción de Gracias, hechas por hombres de Estado y de Iglesia. Sus pretensiones fueron que el Gobierno nombrara capellanes para el ejército y para los órganos legislativos, que apoyara la educación y organización religiosa general, así como que garantizara una moral de base religiosa, por medio de normas positivas.

Estas ideas fueron del agrado del Congreso Continental, que autorizó el nombramiento de capellanes para el ejército y los órganos legislativos, financiados con dinero público; también se autorizó el destino de fondos a escuelas religiosas y a misioneros, el establecimiento de vínculos diplomáticos con el Vaticano, el rezo de oraciones en sus sesiones de apertura y diversas proclama-

61 «etter of John Adams to a Unit of the Massachusetts Militia (1798)», en ADAMs, Works, 9:229.

62 Dwight, T., «The Duty of Americans at the Present Crisis, Illustrated in a Discourse Preached on the Fourth of July, 1798», en E. Sandoz (ed.), Political Sermons of the American Founding Era, $2^{a}$ ed. Liberty Fund. Indianapolis, 1998, 1380.

63 Franklin, B, «Proposals Relating to the Education of Youth in Pensilvania (1749)», citado y comentado en MarTY, M. E., «On a Medial Moraine: Religious Dimensions of American Constitutionalism», Emory Law fournal, 39 (1990), 9-20, at 16-17; BELLAH, R. N., «Civil Religion in America», Dedalus, 96, no. 1 (1967), 1-21; BELLAH, R. N., «The Final Word: Can Christianity Contribute to a Global Civil Religion?», en J. Witte, Jr. y F. S. Alexander (eds.), Christianity and Human Rights: An Introduction, Cambridge University Press, 2010, 357-69. 
ciones para los Días de Acción de Gracias ${ }^{64}$. En 1787, este mismo Congreso Continental también aprobó la Ordenanza del Noroeste que, en una de sus disposiciones, estipulaba: «Siendo la religión, la moralidad y el conocimiento, necesarios para el buen gobierno y la felicidad de la humanidad, se fomentarán siempre tanto las escuelas como la educación en general $\gg^{65}$.

Estos criterios recibieron también un fuerte apoyo de los estados de la Unión. La mayor parte de los cívico-republicanos aprobaban el apoyo del Estado a las instituciones religiosas, así como que se les diera cabida dentro del ordenamiento, ya que se las consideraba como aliadas cruciales para el buen gobierno y como agentes esenciales del bien común. Nathan Strong predicó que «la religión y sus instituciones son la mejor ayuda para el gobierno, al fortalecer la mano del gobernante y al conseguir que el súbdito permanezca leal en su puesto y sea obediente a las leyes generales» ${ }^{66}$. De modo similar, el senador de Connecticut, Oliver Ellsworth, declaró: «Las instituciones para la promoción de la buena moral son objeto de regulación y apoyo legislativo: y entre éstas... las instituciones religiosas son eminentemente útiles e importantes ${ }^{67}$. El predicador de Pennsylvania Thomas Reese estaba «completamente convencido de la utilidad, e incluso de la necesidad de la religión para el bienestar»e incluso para «la misma existencia de la sociedad civil». Y esto porque la religión proporciona a los ciudadanos la comprensión de lo que es «la recompensa y el castigo», «el autocontrol y el respeto» y la lealtad y el deber, todos los cuales son esenciales para «una sociedad consagrada a la vida, la libertad y la búsqueda de la felicidad $\gg^{6}$. Por todo ello, los cívicorepublicanos apoyaban las exenciones fiscales para las propiedades eclesiales y la financiación pública de las escuelas con orientación religiosa, las instituciones de beneficencia y los misioneros; las donaciones de terrenos públicos para

64 Davis, D.H., Religion and the Continental Congress, 1774-1789: Contributions to Original Intent, Oxford University Press, Oxford, 2000. Vid. numerosas resoluciones recogidas en Dreisbach y Hall (eds.), The Sacred Rights of Conscience, Liberty Fund., Indianapolis, 2009, 215-39.

65 Artículo III, 1 Stat. 50, 51-53, cap. 8. Sobre los diveros borradores anteriores de la Ordenanza del Noroeste, empleando unos términos más expansivos, vid. Gaustad, E. S., Faith of the Founders: Religion and the New Nation, 1776-1826, 2ª ed., Baylor University Press, Wako, 2004, 115-17, 151-56.

66 STRONG, N., Election Sermon (1790), 15.

67 The Public Records of the State of Connecticut, Christopher Collier (ed.), Connecticut State Library, 1967, 11:371, 373.

68 REESE, Th., An Essay on the Influence of Religion in Civil Society (1788), en Dreisbach and Hall (ed.), The Sacred Rights of Conscience, 316-35. 
las entidades religiosas, así como protecciones penales contra la blasfemia, el sacrilegio y la perturbación de los servicios religiosos.

John Adams fue un importante e influyente impulsor de estas ideas cívicorepublicanas, al buscar un equilibrio entre garantizar la necesaria libertad para todas las religiones privadas y una forma «ligera y equitativa» de religión pública oficial, que consideraba esencial para la prosperidad de la ciudadanía. Debemos ciertamente comenzar «liberando la conciencia», escribió Adams, porque «cuando todos los hombres, de todas las religiones conformes con la moral y la propiedad, gocen de igual libertad,... [y] de seguridad para su propiedad, así como de las mismas oportunidades de alcanzar honores y poder... entonces podremos esperar que se produzcan mejoras en el carácter humano y en el estado de la sociedad». Más aún, la existencia de una pluralidad de religiones en la comunidad proporciona la mejor salvaguarda contra la persecución religiosa ${ }^{69}$. Sin embargo, exactamente de la misma manera que debemos garantizar la libertad de todas las religiones privadas, insistió Adams, debemos establecer una «religión [pública] en primera línea de la sociedad y del estado». Los gobernantes pueden planificar y especular a favor de la libertad, pero son sólo la religión y la moral las que pueden instaurar los principios sobre los cuales la libertad puede descansar con seguridad. «La religión y la virtud son los únicos fundamentos, no sólo del republicanismo y de todo estado libre, sino también de la felicidad social, conforme a todo tipo de gobiernos y en todo tipo de humana sociedad $\gg^{70}$.

Adams insertó estos principios en la Constitución de Massachusetts de 1780 la cual, ampliamente reformada, es la más antigua constitución del mundo que haya permanecido en vigor ininterrumpidamente. Su artículo II establecía: «Es un derecho, tanto como un deber de todos los hombres en sociedad, en público y en momentos concretos, el adorar al Ser Supremo, el gran Creador y Conservador del Universo». El artículo III establecía el motivo de lo anterior: «La adoración pública a Dios y la formación en la piedad, la religión y la moralidad... promueven su felicidad y aseguran... el buen orden y la conservación de su gobierno» ${ }^{71}$. Esta misma Constitucion también insistió

69 Carta a Thomas Jefferson (June 25, 1813), en The Adams-fefferson Letters, 2 vols., L. J. Cappon (ed.), Omohundro Ins. 1959, 1:333, 334.

70 ADAMS, Works, 8:232; 9:401, 635, 636.

71 Constitución del estado de Massachusetts (1780), Parte I, Arts. II and III; esta terminología se conserva en el Amendment, Art. XI (1833), que reemplazó la Parte I, Art. III. Vid. WiTTE Jr. J.,, «'A Most Mild and Equitable Establishment of Religion': John Adams and the 1780 Massachusetts Constitution», Fournal of Church and State, 41 (1999), 213. 
en que todas las personas, en particular los líderes políticos, debían mantener criterios exigentes de conducta moral y religiosidad, que deberían confirmar públicamente cuando juraran sus cargos. También transformaba estas mismas cualidades morales en ingredientes esenciales de la educación estatal, dado que «el impulso a las artes y a las ciencias, así como a toda buena literatura, tiende a honrar a Dios, a promocionar la religión cristiana y a beneficiar más a éste y a los otros Estados Unidos de América».

\section{A MODO DE CONCLUSIÓN}

Estas cuatro perspectivas -puritana, evangélica, ilustrada y cívico-republicana- contribuyeron a configurar el experimento estadounidense en materia de derechos y libertades religiosas, en su primera fase. Los líderes a nivel nacional y estatal las asumieron con generosidad como propias, en los albores de la república norteamericana. Lo hicieron de modo informal en cartas y panfletos y, formalmente, durante la Convención Constitucional y los debates de ratificación. Cada una de estas cuatro perspectivas dejó improntas indelebles en los documentos constitucionales, así como en el posterior desarrollo del primer Derecho constitucional norteamericano.

El punto de partida común de estas cuatro perspectivas fue el rechazo del anglicanismo como religión oficialmente establecida. Este carácter oficial había formado parte del Derecho positivo de las colonias norteamericanas hasta la Revolución norteamericana. El anglicanismo como religión oficial amalgamaba Iglesia y república en una sociedad uniforme. El Rey era su suprema Cabeza. Los obispos eran miembros del Parlamento. El clero anglicano recibía nombramientos de carácter político; eran titulares de numerosas exenciones y privilegios especiales, de contribuciones fiscales y diezmos, de parroquias y beneficios, financiados por el Estado. El Parlamento inglés aprobaba leyes eclesiásticas y los tribunales de la Iglesia las aplicaban. El Parlamento también establecía la doctrina de la nación, la liturgia y los textos canónicos. El Derecho penal aseguraba el cumplimiento de la moral religiosa, reglamentaba el culto y los juramentos de lealtad y protegía las propiedades y al clero de la Iglesia oficial. La condición de fiel estaba ligada a la condición de ciudadano; la herejía era una forma de traición. La ley toleraba a los disidentes religiosos protestantes, pero éstos eran sometidos a impuestos y restricciones especiales. Los judíos y los católicos carecían de todo reconocimiento legal. Ninguno de los más importantes pa- 
dres fundadores de la nación norteamericana deseaba esta forma de pleno establecimiento oficial de una religión ${ }^{72}$.

Los puritanos y los cívico-republicanos sólo querían un «ligero y equitativo» establecimiento oficial de una religión. Los puritanos pretendían que cada comunidad local estableciera sus propios y distintos ideales religiosos y morales, protegidos por la Iglesia local y por las autoridades estatales, frente a las religiones disidentes. Los cívico-republicanos peleaban por una más genérica forma de religión, que el Estado asumiría por motivos de utilidad y conveniencia. Los mayores exponentes evangélicos e ilustrados se oponían a cualquier tipo de religión oficial y exigían una más fuerte separación entre Iglesia y Estado. La mayor preocupación de los evangélicos era proteger a la religión y a la Iglesia, frente a la política y el Estado. La mayor preocupación de los ilustrados era proteger la política y el Estado, frente a la religión y la Iglesia.

Puede decirse, a modo de conclusión que a pesar de sus diferencias (puritanos y cívico-republicanos definían de modo más restringido los principios de libertad religiosa en tanto que los evangélicos e ilustrados los interpretaban con mayor amplitud) los más importantes exponentes de estas cuatro perspectivas rivales apoyaron la libertad de conciencia, el derecho a la libre práctica religiosa y la igualdad para todo un abanico de religiones rivales.

72 Sobre la variedad de religiones en Norteamérica, en ese momento, vid. STEIN, S. J. (ed.), The Cambridge History of Religions in America, Volume 1: Precolumbian Times to 1790, Cambridge University Press, 2012. 
0000 


\section{NORMAS PARA EL ENVÍO DE ORIGINALES}

\section{NORMAS EDITORIALES}

Persona y Derecho se edita principalmente en español, aunque también se aceptan y publican trabajos en inglés, francés, portugués e italiano.

\section{Artículos}

Los artículos, cuyo contenido ha de ser ORIGINAL, se presentarán mecanografiados a espacio y medio, en formato papel A4. Se utilizará el tipo de letra Calibri, Arial o Times New Roman, tamaño 11 (once) para el texto principal y 9 (nueve) para las notas. Su título, un resumen y una selección de palabras clave figurarán en el idioma original del texto y en inglés científico. Los trabajos no necesitarán tener sumario. La extensión mínima del texto del artículo será de 50.000 caracteres con espacios y la máxima de 90.000 . Tal extensión es recomendable, pero ha de ser entendida como regla general. El resumen deberá tener entre 500 y 1.200 caracteres y se admitirán hasta 20 palabras clave.

No deberá figurar en los trabajos un apartado final con bibliografía o referencias bibliográficas. Todas las referencias se harán en notas de pie del siguiente modo:

- Libro: ApELlido, Inicial del nombre, Título de la obra, Editorial, Ciudad, año, número de página/s (p./ pp.). Ejemplo: Hervada, J., Introducción crítica al derecho natural, Eunsa, Pamplona, 1994, p. 13.

- Capítulo en obra colectiva: APELLIDO, Inicial del nombre, «Título del capítulo», en APELLIDO, Inicial del nombre (eds.), Título de la obra, Editorial, Ciudad, año, número de página/s (p./pp.). Ejemplo: PALAZZANI, L., «Los valores femeninos en bioética», en Aparisi, A.; Ballesteros, J., Por un Feminismo de la Complementariedad, Eunsa, Pamplona, 2002, pp. 55-76.

- Artículo de revista: ApELLido, Inicial del nombre (s), «Título del artículo», Título del periódico o revista, vol., $\mathrm{n}^{\circ}$, mes y año, número de página(s) (p./pp.). Ejemplo: MASsINI, C. I., «La interpretación jurídica como interpretación práctica», Persona y Derecho, 52 (junio, 2005), pp. 413-433.

- En las citas de fuentes electrónicas, después del autor y del título hay que especificar la dirección completa de URL dentro de los signos $<>$, la fecha de su aparición en la red o de la última revisión y entre paréntesis la fecha de acceso al documento de la fuente para su cita. En los documentos extensos que no tengan número de página, se indicará en su lugar la sección, el párrafo y el número de línea. Han de respetarse las mayúsculas, minúsculas, barras y espacios de la dirección, no separando los elementos ni acabando las direcciones con un punto. Ejemplo: D’Agostino, Francesco, «Bioética y Persona», < http://www. aebioetica.org/rtf/01bioetica53.pdf >, 2004 (12 de mayo de 2009).

\section{Recensiones}

Se recibirán recensiones de obras recientes y afectas a los ejes temáticos de la revista, que se presentarán en el mismo formato de los artículos. La extensión mínima del texto de la recensión será de 6.500 caracteres con espacios y la máxima de 15.000. Tal extensión es recomendable, aunque no obligatoria.

Habitualmente los plazos de entrega de los originales para publicación en el número siguiente son 15 de marzo y 15 de septiembre. Las normas editoriales vigentes siempre estarán disponibles en http://bit.ly/pydnormas. Se recomienda su comprobación antes de realizar el envío de trabajos.

\section{LISTA DE COMPROBACIÓN}

Los autores deberán comprobar que su envío cumple cada uno de los siguientes requisitos:

1. El texto presentado no ha sido publicado previamente, ni se ha enviado a otra revista;

2. Se incorpora la traducción al inglés científico del título y el resumen, En caso de que el inglés no sea correcto se devolverá al autor;

3. El fichero está en formato Microsoft Word (DOC y DOCX) o RTF;

4. Se han añadido direcciones web para las referencias, donde ha sido necesario;

5. El texto cumple con los requisitos bibliográficos y de estilo indicados;

6. Los autores del documento han eliminado sus nombres del texto, utilizando «Autor»y año en las referencias y en las notas al pie de página, en vez del nombre del autor, el título del artículo, etc.

7. Con los documentos de Microsoft Word, la identidad del autor debe ser eliminada también de las propiedades del archivo.

\section{ENVÍO}

Los artículos se enviarán online a través de la plataforma OJS disponible en http://bit.ly/pydenvío. Para más informaciones, solución de dudas y otras remas relacionados con Persona y Derecho se puede acceder la página web http://bit.ly/pydunav o escribir a pyd@unav.es.

Aparte de la revisión editorial, que tiene por finalidad comprobar si se cumplen los requisitos formales señalados, el contenido de los trabajos será objeto de una evaluación científica por especialistas ajenos al Equipo Editorial, por medio de un proceso que preservará el anonimato de autores y evaluadores. 
0000 